\title{
The state of psychogeriatrics in Europe: challenges and opportunities in six European countries
}

With the increase in aging all over the world, and the elderly population nearly tripling from 524 million ( $8 \%$ of the world's population) in 2010 to 1.5 billion ( $16 \%$ of the world's population) in 2050, we will face new challenges and opportunities in providing healthcare. In 2050, it is estimated that Europe will see an increase of $70 \%$ in elderly population aged over 65 years, and $170 \%$ in those aged over 80 years (World Health Organization (WHO), 2011). It is vital to respond to the needs of this emerging population and the consequent rise in chronic diseases, especially dementia and mental health disorders, which will overload the healthcare system, as well as raise health and social costs, and demand new policies from national governments (World Health Organization, 2012). We urgently need to know how to organize healthcare for elderly people in the years to come.

The present study was initiated under the umbrella of the President's Forum, organized by the International Psychogeriatric Association (IPA) at its International Congress in 2011 in The Hague, the Netherlands, where challenges and opportunities were discussed by IPA-affiliated national psychogeriatric associations. Between 2011 and 2012, these 20 IPA affiliates were invited to submit a written report, resulting in the first paper (Wang et al., 2013). Based on this, a comparative study about the current state of psychogeriatrics with particular focus on the six European affiliates' (Portugal, Spain, United Kingdom, the Netherlands, Norway, and Switzerland) reports was carried out. In this study, a qualitative analysis, using the NVivo program (QSR International, 2013) was performed, focusing on the needs for the development of psychogeriatrics, strengths and resources, and the definition of an action plan in each country.

\section{Needs for the development of psychogeriatrics}

The cost of dementia, estimated at over EUR 250 billion per year by 2030, is currently provided largely by family caregivers, but will soon be borne by public health services (Jönsson and Wimo, 2009). Services specializing in older people's mental health (community mental health teams, primary care, care homes, inpatient care, general hospitals, crisis intervention services, and memory clinics) and trained clinicians practicing in geriatrics and old age psychiatry (OAP) will be needed (Jönsson and Wimo, 2009).

There is great variability in geriatric mental health services, network-based care, and accessibility in Europe, associated with type of healthcare system, geographic area (rural vs. urban), use of residential placement, and patient characteristics. There is also a lack of data about treatment options and preferences, e.g. in the range from biological to psychological therapies. Collaboration is lacking between general practice and specialized medicine (geriatric medicine, nursing home medicine, geriatric psychiatry, and neurology, among others). Affiliates identified a need for old age mental health services in general hospitals/departments of geriatric psychiatry (inpatient care for delirium, behavioral and psychological symptoms of dementia (BPSD), liaison psychiatry services, etc.), as well as in primary care and community-based mental health services (outpatient settings, outreach teams, and community mental health teams), and finally in long-term care facilities and nursing homes (Warner, 2014).

National mental health strategies for the elderly were regarded as important, but only four of the six countries responding had integrated psychogeriatric service models (United Kingdom, Norway, Switzerland, and the Netherlands) with well-defined programs.

However, fewer responses or actions than expected from mental health strategies were registered, with discordant policies between countries (United Kingdom, Spain, and Switzerland), particularly related to mental and physical healthcare and social support services. Responses included poor coordination between research, policy, and service delivery; a need to improve links between specialist services and primary care, where most mental disorders in older people first present; a need for implementation of basic care networks of geriatrics and geriatric psychiatry; increased resources in the field of geriatric psychiatry; and the importance of multidisciplinary interventions. 
Limited funding and lack of human resources and facilities were constraining the promotion of education in geriatrics, psychiatry, general practice, and allied health professions (nursing, psychology, and social work, among others) as well as for formal and informal caregivers. The Internet was reported to be an important and promising tool, particularly with the application of electronic devices to deliver care.

Specific training in geriatric psychiatry was reported as a requirement. Some nations have well-established training and education programs (United Kingdom, Switzerland, Norway, and the Netherlands); others are in the process of development (Spain and Portugal).

The recognition of geriatric psychiatry as a specialist discipline varied across Europe, and is on the rise. In countries with formal recognition of the OAP specialty training programs were specific to the country. Harmonization across Europe was pinpointed as a need by developing a common curriculum with a standardized program of training, continuous professional development and supervision for OAP, counseling, and practice. It is also unfortunate that there is no consensus on the terminology used such as OAP, psychogeriatrics, geriatric psychiatry, etc.

While geriatric psychiatry/OAP was seen as a subspecialty of psychiatry rather than as part of geriatrics, training programs across Europe were heterogeneous, with some nations having a highly differentiated system of training (e.g. United Kingdom, the Netherlands, Norway, and Switzerland) and others not differentiating without subspecialization (e.g. Portugal and Spain). In the United Kingdom, OAP was started as a group, then in 1973 it changed into faculty, and in 1989, the UK government/National Health Service recognized it as a specialty (Arie and Jolley, 1999).

Old age psychiatry is not recognized as a specialty by the European Union, which impedes its development across Europe even though there is evidence from Norway that improved competence in geriatric psychiatry results in a higher quality of patient treatment services at a lower cost (Norwegian Psychiatric Association (NPA), 2011).

Promotion of research was also identified as a need, focusing on the importance of collaborations with regional and international academic centers and institutions. Most countries recognized lack of research supervisors, limited opportunities for research training, and scarce participation in multicenter research (at national and international levels). Besides the present focus on diseasemodifying studies for Alzheimer's disease and mild cognitive impairment, there is a need for the development of other lines of research, e.g. psychiatric comorbidity with physical diseases, and psychosocial and pharmacological treatments for psychiatric conditions in old age. The quality of research can be enhanced by internal departmental, intranational, and international collaborations.

\section{Available strengths}

Most affiliated national psychogeriatric associations reported that they had connections with local service resources, geriatric, psychiatric, and psychological services, nursing, and Alzheimer's societies. A few psychogeriatric services were well integrated with well-established structures and relevant standards (United Kingdom, Norway, the Netherlands, and Switzerland).

Published guidelines included Inpatient care for old people within the mental health service (Royal College of Psychiatrists (RCPsych), 2006a) or "community mental health teams" (CMHT; Royal College of Psychiatrists, 2006b). RCPsych also developed accreditation standards/services to assess older people's inpatient services (AIIMS) and memory assessment services (MSNAP).

Affiliates have endeavored to build service capacity in old age mental health. National organizations have developed training activities with courses, seminars, workshops, annual conference meetings, and journals. Most activities were developed in collaboration with international associations (IPA and European Association of Geriatric Psychiatry (EAGP)). A remarkable strength is the fact that Europe has the oldest association of geriatric psychiatry: the EAGP, founded in 1971, with 44 European national members. Against this background, fundamental guidelines have been developed by EAGP together with the WHO, videlicet The Old Age Psychiatry Consensus on Ethics and Capacity in Old People with Mental Disorders (Katona et al., 2009). International guidelines on the treatment of dementia (Ihl et al., 2011) and a survey of geriatric psychiatry training across Europe (Toot et al., 2012) have emerged more recently. The best-known educational curriculum has been developed by the World Psychiatric Association (WPA) and the WHO (1998), appearing as one of the main strengths in training in geriatric psychiatry.

In spite of great variation in the OAP training, the focus of the debate has been the educational curriculum of OAP rather than skills- or practicebased training program. In this context, a proposed core curriculum based on knowledge, in addition to skills-based objectives for specialist training in OAP, has been agreed upon by the EAGP and the WHO (Gustafson et al., 2003). Several options for harmonizing the OAP training in Europe were identified: a Master of Science (MSc) in geriatric 
psychiatry recognized across Europe (e.g. Spain), a common core curriculum based on knowledge and skills to define the specialty of OAP and peer review panels to supervise and critically appraise consultant OAP and those in training (an ongoing process and mutual exchange of knowledge and expertise; UK and Switzerland) (Toot et al., 2012). The Bologna Agreement (2010), which outlines a system of comparable and understandable qualifications, resulted in the promotion of student mobility and geriatric psychiatrists being able to work freely across these countries. In this context, recognition of diplomas, certificates, and formal education is a priority (Toot et al., 2012).

\section{Plan of action}

A plan of action was designed attributing a leading role to IPA based on the following priorities:

- Promotion of joint global strategies, guidelines, and consensus recommendations, such as the "Lausanne Technical Consensus Statements on Psychiatry of the Elderly" (World Health Organization, 1999).

- Endorsement of national or international initiatives compatible with joint effort to facilitate lobbying directed toward professional and political decision makers to achieve better and integrated policies in OAP.

- Achieving global recognition of geriatric psychiatry as a subspecialty.

- Promotion and accreditation of national or international education programs.

- Promotion and financing of international exchange of geriatric psychiatry programs (at graduate and postgraduate levels).

- Collaboration on international research networks, particularly with IPA affiliates, the EAGP, and the WHO.

- Promotion of research in geriatric psychiatry with projects possibly led by IPA and aiming for international publications.

- Helping the affiliate organizations in countries with less developed psychogeriatrics, with support of research funding (e.g. grants and fellowships).

- Sharing with former pioneers' references, the expertise for consultation and education in local trainings.

- Participation of international opinion leaders in education and scientific conferences, continuing medical education (CME) programs, subspecialty training courses, and online education. IPA should act as an international leader in psychogeriatrics in international forums related to mental health of the elderly.

- Advocacy to influence the political process in Europe to improve mental health services for older people and strengthen national associations and their members with financial support.
The aim of these measures is to convince national political decision makers to contribute to globally integrated policies for mental health in the elderly, promote national strategies in OAP with cost-effective services, share expertise, provide quality and accreditation for national psychogeriatric services, and promote national programs for the cases of dementia.

\section{Conclusions}

There is a great need for the development of strategies for mental health services to meet the challenge that the global increase in the elderly, with inevitably more dementia and mental disorders, poses for communities. It is crucial to develop more specialized psychiatric services and centers of excellence, as well as to establish expertise in hospitals, departments of geriatric psychiatry, primary care, communitybased mental health services, consultation-liaison services, mental health services in long-term care, nursing homes, and memory clinics.

Development of education in geriatric psychiatry with a defined international core curriculum extended to all professionals involved in elderly care and professional settings and the public is fundamental. At the same time, it is important to promote research into cause, prevention, management, and care of mental disorders in old age. Finally, to face all these European challenges, it is crucial to collaborate with international organizations, especially IPA, EAGP, WHO, and Alzheimer's Disease International (ADI).

\section{Participating IPA-affiliated psychogeriatric associations}

Royal Australian and New Zealand College of Psychiatrists - Faculty of Psychiatry for Old Age (RANZCP-FPOA; Roderick McKay), Psychogeriatric Interest Group, Chinese Society for Psychiatry (CPIG; Xin Yu and Huali Wang), Hong Kong Psychogeriatric Association (SiuWa $\mathrm{Li}$ and Helen Chiu), Indian Association for Geriatric Mental Health (IAGMH; Charles Pinto), Indonesian Psychogeriatric Association (Martina WS Nasrun), Korean Association of Geriatric Psychiatry (KAGP; Maeng Je Cho and Changsu Han), Taiwanese Society of Geriatric Psychiatry (Yung-Jen Yang and Te-Jen Lai), Thai Society for Geriatric Psychiatry and Neuropsychiatry (TSGN; Nahathai Wongpakaran and Pichet Udomratn), The Dementia Association (Thailand; Vorapun Senanarong), *Portuguese 
Gerontopsychiatric Association (Lia Fernandes), * The Spanish Psychogeriatric Association (Raimundo Mateos), ${ }^{*}$ Faculty of Old Age Psychiatry, RCPsych, London, UK (Anand Ramakrishnan), * Department of Old Age Psychiatry Netherlands Psychiatric Association (Max L. Stek), *NPA (Knut Engedal), *Swiss Society for Old Age Psychiatry (Armin von Gunten), *EAGP (Ralf Ihl), and Brazilian Association of Geriatric Neuropsychiatry (Sónia Brucki) (asterisks indicate those participating in European survey).

\section{Conflict of interest}

None.

Lia FERNANDEs, ${ }^{1}$ RAIMUNDO MATEOS, ${ }^{2}$ KNUT ENGEDAL, ${ }^{3}$ ARMIN VON GUNTEN, ${ }^{4}$ MAX L. STEK, ${ }^{5}$ ANAND RAMAKRISHNAN, ${ }^{6}$ RALF IHL, ${ }^{7}$ HUALI WANG, ${ }^{8}$ JACOBO MINTZER ${ }^{9}$ AND HENRY BRODATY ${ }^{10}$, on behalf of the President Forum Working Group of International Psychogeriatric Association

${ }^{1}$ UNIFAI/CINTESIS, Faculty of Medicine, University of Porto, Portugal

${ }^{2}$ Departamento de Psiquiatría, Facultad de Medicina de Santiago de Compostela, Spain

${ }^{3}$ Norwegian Centre for Aging and Health, Vestfold Hospital Trust, Toensberg, Norway

${ }^{4}$ Service Universitaire de Psychiatrie de l'âge Aavancé, Département de Psychiatrie, Lausanne University Hospital, Prilly-Lausanne, Switzerland

${ }^{5}$ Department of Old Age Psychiatry - Academische

Werkplaats Ouderenpsychiatrie GGZ inGeest/VUmc, the Netherlands

${ }^{6}$ Faculty of Old Age Psychiatry, Royal College of

Psychiatrists, London, UK

${ }^{7}$ Department of Psychiatry and Psychotherapy, University of Düsseldorf and Alexian Research Center Krefeld, Germany

${ }^{8}$ Key Laboratory for Mental Health, Ministry of Health, Peking University Institute of Mental Health, Beijing,

China

${ }^{9}$ Clinical Biotechnology Research Institute, Roper St.

Francis Healthcare and Ralph H. Johnson VA Medical Center, Charleston, South Carolina, USA

${ }^{10}$ Centre for Healthy Brain Ageing, University of New

South Wales, Sydney, Australia

Email: lfernandes@med.up.pt

\section{Acknowledgment}

The authors thank Pedro Teixeira and Rita Leal for advice on qualitative analysis.

\section{References}

Arie, T. and Jolley, D. J. (1999). Psychogeriatrics. In H. Freeman (ed.), A Century of Psychiatry (pp. 260-265). London: Morby-Wolfe.

Bologna Agreement. (2010). The official Bologna Process website. Available at: http://www.ond.vlaanderen.be/ hogeronderwijs/bologna/; last accessed 1 August 2011.

Gustafson, L. et al. (2003). Skill-based objectives for specialist training in old age psychiatry. International fournal of Geriatric Psychiatry, 18, 686-693. doi:10.1002/ gps.899.

Ihl, R. et al. (2011). World Federation of Societies of Biological Psychiatry (WFSBP) guidelines for the biological treatment of Alzheimer's disease and other dementias. World Fournal of Biological Psychiatry, 12, 2-32. doi:10.3109/15622975.2010.538083.

Jönsson, L. and Wimo, A. (2009). The cost of dementia in Europe: a review of the evidence, and methodological considerations. Pharmacoeconomics, 27, 391-403. doi:10.2165/00019053-200927050-00004.

Katona, C. et al. (2009). World psychiatric association section of old age psychiatry consensus statement on ethics and capacity in older people with mental disorders. International fournal of Geriatric Psychiatry, 24, 1319-1324. doi:10.1002/gps.2279.

Norwegian Psychiatric Association. (2011). Plandokument for Norsk Alderspsykiatri 2011-2020. Oslo, Norway: Norwegian Psychiatric Association.

QSR International. (2013). NVivo 10 for Windows. Available at: http://www.qsrinternational.com/; last accessed 1 August 2013.

Royal College of Psychiatrists. 2006a. Inpatient Care for Old People Within the Mental Health Service, Faculty report FR/OA/1. London: RCPsych.

Royal College of Psychiatrists. 2006b. Raising Standards, brochure. London: RCPsych.

Toot, S., Orrell, M., Rymaszewska, J. and Ihl, R. (2012). A survey of geriatric psychiatry training across Europe. International Psychogeriatrics, 24, 803-808. doi: $10.1017 /$ S1041610211002341.

Wang, H. et al. (2013). The state of psychogeriatrics in different regions of the world: challenges and opportunities. International Psychogeriatrics, 25, 1563-1569. doi: $10.1017 /$ S1041610213001002.

Warner, J. (2014). Wither old age psychiatry? International Psychogeriatrics, 8, 1-4.

World Health Organization. (1999). Lausanne Technical Consensus Statements on Psychiatry of the Elderly. Geneva, Switzerland: World Health Organization.

World Health Organization. (2011). Global Health and Aging. National Institute on Aging. National Institutes of Health. Geneva, Switzerland: World Health Organization.

World Health Organization. (2012). Dementia - A Public Health Priority. Geneva, Switzerland: World Health Organization.

World Psychiatric Association and World Health Organization. (1998). Education in Psychiatry of the Elderly: A Technical Consensus Statement. Geneva, Switzerland: World Health Organization. 